https://doi.org/10.46344/JBINO.2021.v010i01.18

\title{
TEMOZOLOMIDE AFLOAT MICROSPHERES FOR CARCINOMA OF THE BRAIN: FABRICATION AND CHARACTERIZATION
}

\author{
Hindustan Abdul Ahad*, Chinthaginjala Haranath, Ksheerasagara Tarun, Samhitha Rao, Dasari Rahul \\ Raghav, Pandyala Sravanthi \\ Department of Industrial Pharmacy, Raghavendra Institute of Pharmaceutical Education and Research (RIPER)-Autonomous, \\ Ananthapuramu - 515721, Andhra Pradesh, India
}

Email: abdulhindustan@gmail.com

\begin{abstract}
Floating microspheres (FM) of Temozolomide (TZM) were made to build its scope to achieve good blood concentration and to show lengthened medication discharge. FM of TZM was set up by lon gelation strategy utilizing ethyl cellulose, Carrageenan gum, and sodium alginate. The medication stacked FM were structured and evaluated for its physicochemical attributes including drug-excipient inviting conduct by Differential Scanning Calorimetry (DSC) and Fourier Transform Infra-red (FTIR). The DSC and FTIR study uncovered the similarity of TZM with the excipients utilized. The rate yield of FM from all details was acceptable and demonstrated palatable lightness and coasting time. \% TZM discharge for the FM was found up to $98.25 \%$ (F-8) till tenth $\mathrm{h}$. The investigation infers that FM with TZM can be figured utilizing sodium alginate, ethyl cellulose, and carrageenan gum by exfoliation technique.
\end{abstract}

Keywords: Temozolomide, carrageenan, microspheres, buyout 


\section{INTRODUCTION}

The floating drug delivery systems (FDDS) is intended for gastrointestinal maintenance for a long length (Ahad et al., 2011). Gastro holding of solid dosage forms can be accomplished by the creations of adjusted density, bodily fluid attachment, development, unfurling, and so on (Meka et al., 2008). Floating Microspheres (FM) with low-density polymers are getting intriguing for many researchers (Harsha et al., 2020).

Temozolomide (TZM) is an alkylating agent given orally to tackle carcinoma of the brain (Barvaux et al., 2004). TZM is of imidazotetrazine derivative, contains imidazole ring fused to tetrazine ring. TZN is a prodrug and converts into an active form in the body. It mainly eliminates by renal and traces by feces (Ashley et al., 2009).

\section{MATERIALS AND METHODS}

\section{Material}

The materials required in this work are delineated in Table 1.

Table 1: List of materials

\begin{tabular}{ll}
\hline Materials & Suppliers/Manufacturer \\
\hline Temozolomide & A gift from Cipla, Hyderabad, \\
& Telangana \\
Sodium alginate & Fischer Chemic Ltd, Hyderabad \\
Ethyl Cellulose & Fischer Chemic Ltd, Hyderabad \\
Carrageenan & Fischer Chemic Ltd, Hyderabad \\
Calcium chloride & Fischer Chemic Ltd, Hyderabad \\
Double distilled water & Own distillation unit \\
\hline
\end{tabular}

The equipment utilized was (table 2) listed.

Table 2: List of equipment used in the study

\begin{tabular}{ll}
\hline Devices & Manufacturers \\
\hline Digital balance & Vibra technologies, Bangalore \\
Magnetic stirrer & Remi, Secunderabad \\
Melting point apparatus & Sisco Ltd. Hyderabad, India \\
DSC scanner & Perkin Elmer \\
FTIR & Bruker alfa \\
UV visible spectroscopy & Shimadzu-S1210 \\
Membrane filter & Millipore \\
\hline
\end{tabular}




\begin{tabular}{ll}
\hline Probe sonicator & Power sonic, Mumbai \\
Dissolution test apparatus & Electro lab USP Tdl-081
\end{tabular}

\section{Drug excipient compatibility studies}

Differential scanning calorimetry (DSC)

The DSC examinations of TZM and definition mix were performed with Perkin Elmer, FTIR spectrophotometer to check any medication excipient collaboration. Each sample was situated in an aluminum skillet discretely with warming paces of $10^{\circ} \mathrm{C} / \mathrm{min}$ from $50-300^{\circ} \mathrm{C}$ under nitrogen $(50 \mathrm{ml} / \mathrm{min}$ ).

\section{FTIR study}

FTIR spectra of TZM and its combination with excipient blend were made by Bruker IR spectrophotometer.

\section{Preparation of FM}

The FM of the TZM was set up by the exfoliation method. The sodium alginate cross-connecting polymers were inundated in water for $24 \mathrm{~h}$. The TZM taken in $10 \mathrm{ml}$ of water broke up and afterward blended in with the above polymer blend. The above arrangement was poured gradually utilizing a 24measure carrageenan needle containing calcium chloride (3\%). The shaped FM was left for $30 \mathrm{~min}$ in the above arrangement with mixing to finish the response and to frame round MS. The readied MS were separated, sprinkled with refined water lastly dried at $45^{\circ} \mathrm{C}$ (Hennink and Franssen, 2002). The dried MS safeguarded in a water/air proof holder (Table 3) (Abdul et al., 2011).

Table 3: Formulations of various FM

\begin{tabular}{lccccccccc}
\hline \multirow{2}{*}{ Ingredients (mg) } & \multicolumn{7}{c}{ Formulations } \\
\cline { 2 - 10 } & F-1 & F-2 & F-3 & F-4 & F-5 & F-6 & F-7 & F-8 & F-9 \\
\hline Temozolomide & 100 & 100 & 100 & 100 & 100 & 100 & 100 & 100 & 100 \\
Sodium alginate & 10 & 20 & 30 & 10 & 20 & 30 & 10 & 20 & 30 \\
Ethyl Cellulose & - & - & - & 10 & 20 & 30 & 10 & 20 & 30 \\
Carrageenan & 5 & 5 & 5 & 10 & 10 & 10 & 15 & 15 & 15 \\
Calcium chloride & 3 & 3 & 3 & 3 & 3 & 3 & 3 & 3 & 3 \\
\hline
\end{tabular}

Characterization of FM

\section{Determination of Entrapment Efficiency}

A $100 \mathrm{mg}$ of $\mathrm{FM}$ were taken, cautiously ground, and suspended in $\mathrm{HCl}$ $(0.1 \mathrm{~N})$. In this way, the substance suspended in the water was kept up by test sonication (Power sonic 505) for 20 min and mixed with a magnetic instigator (Remi) for the entire extraction of the TZM from the FM. The ensuing arrangement was explained through a $0.45 \mu$ film channel (Millipore). The TZM was 
hounded by a UV-visible spectrophotometer (Shimadzu-S1210) at $329 \mathrm{~nm}$. The entrapping was determined by utilizing the accompanying formula (Srivastava et al., 2005).

Drug entrapment efficiency $=\frac{\text { Experimental drug contreet) and maintained at } 37 \pm 0.5^{\circ} \mathrm{C} \text { by }}{\text { The sink conditions. After sufficient }}$ Theoretical drug conteditution, the samples were investigated

\section{Particle size distribution}

Sieve analysis with the help of sieves \# 16, \#20, \#30, \#40, \#60, and \#80 was used to determine by passing the MS from coarse size to finer sieves (Muneer et al., 2017; Kumae et al., 2010).

\section{Buoyancy percentage}

The FM (0.3g) was put in USP XXIV dissolution assembly (type II) loaded up with $900 \mathrm{ml}$ of $0.1 \mathrm{M} \mathrm{HCl}$ with Tween 80 $(0.01 \%)$. The medium was inspired at 100 rpm for $12 \mathrm{~h}$. The drifting and balanced out part of the FM was recouped independently. The FM were emaciated and contemplated. The buoyancy rate was planned as the extent of the majority of the FM that persevered through fluctuating and the complete mass of the FM ( $M a$ et al., 2008; Hindustan et al., 2010).

$\%$ Buoyancy $=\frac{\text { Weight of the FM s }}{\text { Weight of the settled FM }}$ X100

\section{In Vitro Release studies}

for measurement of the TZM at $329 \mathrm{~nm}$ utilizing the Shimadzu UV-VIS double beam spectrophotometer (model: S1210) (Ishaq et al., 2013; Rani et al., 2011). The TZM was measured from the calibration curve as describes by Ishaq et al., 2014.

\section{RESULTS AND DISCUSSIONS}

The TZM thermogram was described by a solitary intense endothermic at $211.78^{\circ} \mathrm{C}$ and the TZM blend demonstrated an endothermic top at $201.84^{\circ} \mathrm{C}$. These thermograms showed that a little change to one side when joined with excipients, this could be attributable to the TZM liquefying or to its transformation into a nebulous structure. These thermograms show that there are no indications of contrariness among TZM and excipients (Fig.1). 


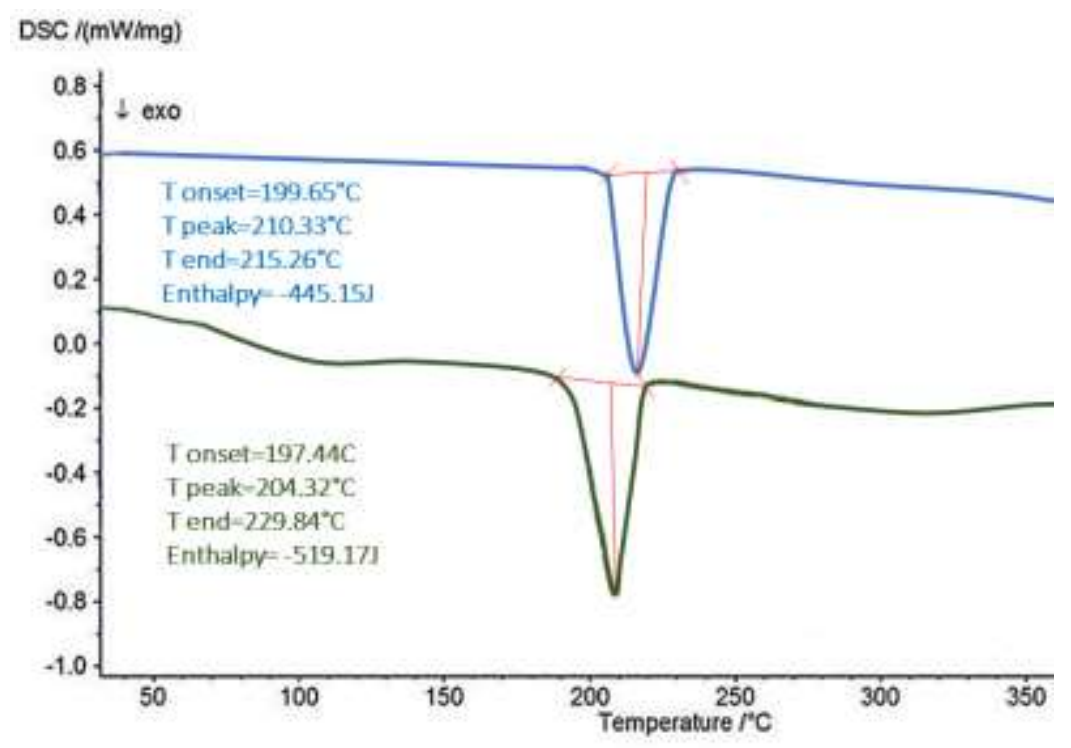

Fig. 1. DSC thermograms of drug and excipient

The FTIR spectra of TZM demonstrated stretches and peaks were likewise in FTIR of TZM-excipient mix represents no remarkable contra issues of TZM with the excipients of the study.

\section{Drug entrapment efficiency (DEE)}

It was discovered that the DEE was acceptable in all the FM at the awakening of $500 \mathrm{rpm}$ (Table 4). The DEE was from $55.95 \pm 0.35$ to $78.07 \pm 0.32 \%$ for $\mathrm{F}-1$ to F-9. The DEE was expanded by climb the polymer focus in FM s. This might be attributable to the low dissolvability of TZM in water, which encourages the dissemination of a piece of the TZM caught in the encompassing during the FM preparation.

\section{Particle size analysis}

The size of the FM differed based on composition (Table 4). The F-1 demonstrated a moderately enormous level of huge size (299.54 $\pm 1.48 \mu)$ and the F-8 detailing indicated fluctuating FM of generally little size $(278.84 \pm 2.69 \mu)$ as the viscidness of the medium raised to a higher polymer fixation, bringing about the improved interfacial strain. The FMs were globular with no noteworthy obvious inconsistency on a superficial level (Table 4).

\section{The Buoyancy Percentage}

The buoyant rate for all FM was $>75 \%$ (for $10 \mathrm{~h}$ ), and ranged from $75.09 \pm 0.02 \%$ to $91.36 \pm 2.16 \%$. The uppermost\% was gained with the plan F8.

Table 4: Efficiency of FM s of Temozolomide FM

\begin{tabular}{|c|c|c|c|c|c|}
\hline Formulation & Yield & Particle & Drug & Buoyancy & Floating \\
\hline
\end{tabular}




\begin{tabular}{cccccc}
\hline & $(\%)$ & Size $(\boldsymbol{\mu})$ & Entrapment $(\%)$ & Percentage (\%) & time (h) \\
\hline F-1 & $65.48 \pm 0.58$ & $299.48 \pm 1.45$ & $56.48 \pm 1.20$ & $75.09 \pm 0.02$ & $5.0 \pm 0.07$ \\
F-2 & $64.58 \pm 1.49$ & $298.54 \pm 1.48$ & $55.95 \pm 0.35$ & $76.26 \pm 1.38$ & $4.8 \pm 0.07$ \\
F-3 & $69.54 \pm 1.05$ & $297.49 \pm 2.25$ & $72.19 \pm 0.68$ & $80.28 \pm 1.65$ & $3.8 \pm 0.05$ \\
F-4 & $71.35 \pm 2.15$ & $287.03 \pm 7.84$ & $68.25 \pm 2.25$ & $81.41 \pm 0.26$ & $5.1 \pm 0.01$ \\
F-5 & $68.57 \pm 1.15$ & $295.98 \pm 2.36$ & $74.49 \pm 0.49$ & $85.22 \pm 0.38$ & $7.3 \pm 0.05$ \\
F-6 & $81.10 \pm 0.65$ & $294.91 \pm 1.20$ & $69.55 \pm 0.31$ & $86.84 \pm 0.13$ & $8.5 \pm 0.11$ \\
F-7 & $69.05 \pm 0.48$ & $299.30 \pm 1.26$ & $67.22 \pm 0.95$ & $78.58 \pm 1.48$ & $7.0 \pm 0.05$ \\
F-8 & $75.84 \pm 0.29$ & $278.84 \pm 2.69$ & $76.04 \pm 0.25$ & $91.36 \pm 2.16$ & $8.9 \pm 0.09$ \\
F-9 & $80.11 \pm 1.49$ & $285.65 \pm 0.67$ & $78.07 \pm 0.32$ & $87.65 \pm 1.49$ & $8.5 \pm 0.05$ \\
\hline
\end{tabular}

Values are in mean \pm SD; Trials made $=3$

\section{Calibration curve}

The TZM concentrations were estimated by the regression equation ( $\mathrm{y}=$ $0.017 x-0.0007, \quad R^{2}=0.9976$ ) of the calibration curve of TZM in $0.1 \mathrm{~N} \mathrm{HCl}(\mathrm{pH}$ 1.2). The calibration curve of TZM was tabulated in table 5 and shown in fig. 2.

\section{In-vitro dissolution study}

The FM s showed a prolonged emission of the TZM in an acidic medium and the release of the TZM was approximately linear. About $40 \%$ of TZM was initially released. Furthermore, the release of the TZM from the FM s matrix was regulated by the polymer. This can reduce the total drug release (DR) from the polymer matrix. Furthermore, the smaller FM are designed at a minor polymer level and has a wider surface wide-open to the dissolution medium, which results in a faster DR (fig.3).

\section{Table 5: Calibration data of drug}

\begin{tabular}{cc}
\hline Concentration $(\boldsymbol{\mu g} / \mathbf{m l})$ & Absorbance $(\mathbf{n m})$ \\
\hline 0 & 0.000 \\
10 & 0.156 \\
20 & 0.356 \\
30 & 0.526 \\
40 & 0.658 \\
50 & 0.852 \\
\hline
\end{tabular}




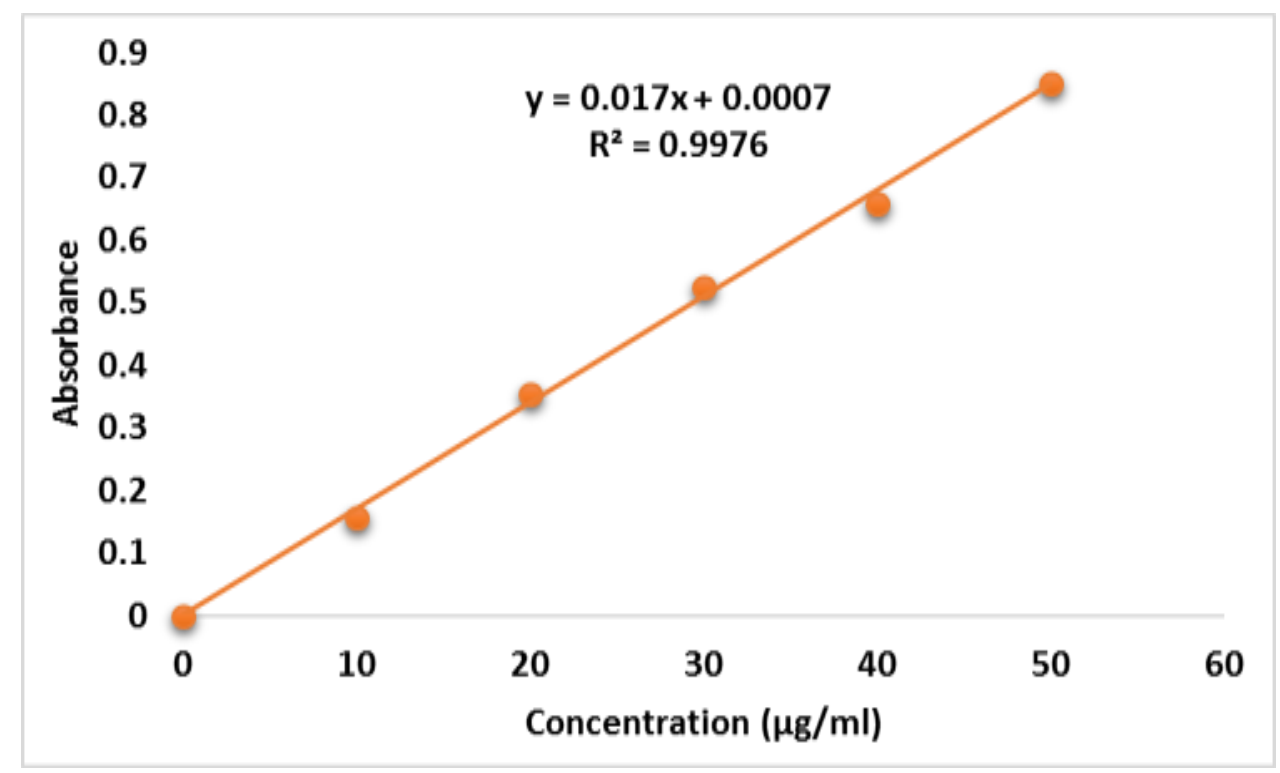

Fig.2. Standard calibration curve of TZM

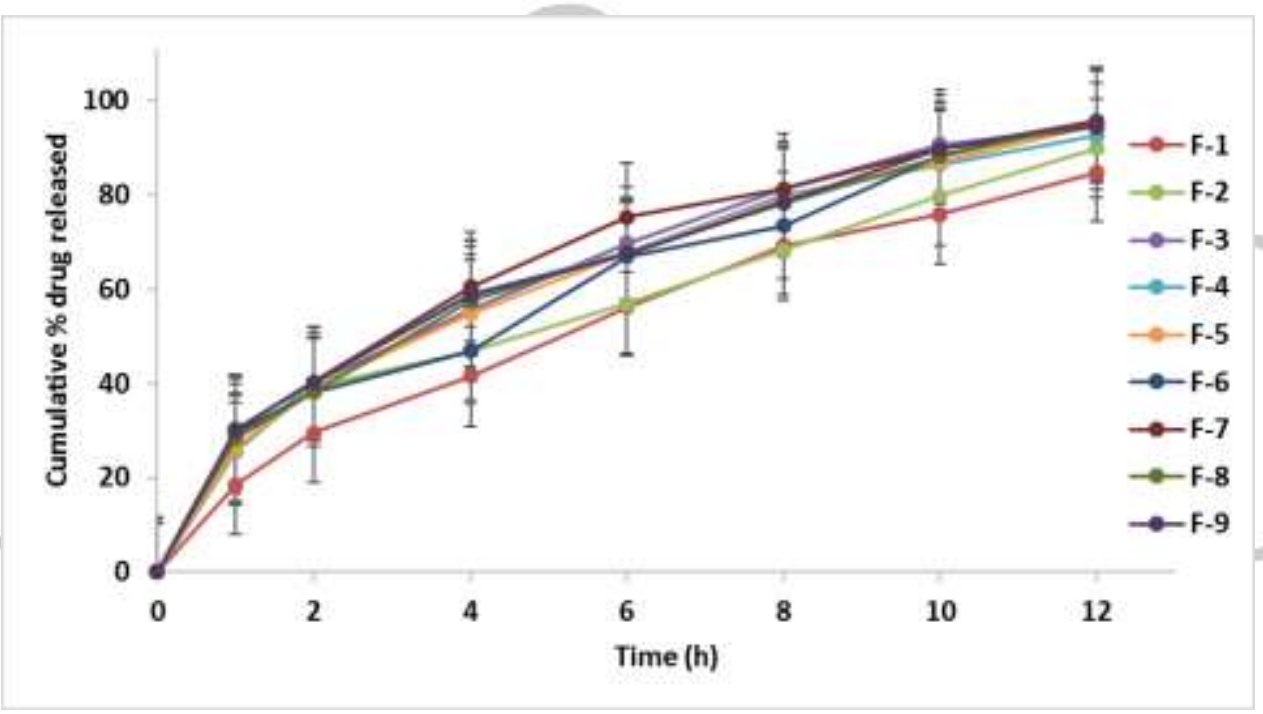

Fig.3. Zero-order plots of TZM

\section{CONCLUSION}

In-vitro data obtained for floating microspheres (FM) of Temozolomide (TZM) displayed good incorporation effectiveness, good buoyancy, and lengthy drug release. The microspheres of various sizes and TZM content could be attained by fluctuating the ingredients. The study concludes that TZM can be formulated as FM using sodium alginate,
Ethyl cellulose and carrageenan gum by ionotropic gelation method. The FM disclosed better buoyancy, and TZM discharge.

\section{REFERENCES}

1. Abdul, A. H.., Sreenivasulu, R., Mallapu Rani, E., \& Reddy, B. V. 
(2011). Preparation and evaluation of famotidine high density gastro retentive microspheres with synthetic and natural polymers. Journal of Pharmaceutical Education \& Research, 2(1).

2. Ahad, H. A., Haranath, C., Rahul Raghav, D., Gowthami, M., Naga Jyothi, V., \& Sravanthi, P (2019). Overview on Recent Optimization Techniques in Gastro Retentive Microcapsules by Factorial Design. International Journal of Pharma Sciences and Research, 10 (9).

3. Ashley, C., \& Currie, A. (Eds.). (2009). The renal drug handbook. Radcliffe Pub.

4. Barvaux, V. A., Lorigan, P., Ranson, M., Gillum, A. M., McElhinney, R. S., McMurry, T. B. H., \& Margison, G. P. (2004). Sensitization of a human ovarian cancer cell line to temozolomide by simultaneous attenuation of the $\mathrm{BCl}-2$ antiapoptotic protein and DNA repair by O6alkylguanine-DNA alkyltransferase. Molecular cancer therapeutics, 3(10), 1215-1220.

5. Harsha, S. S., Ahad, H. A., Haranath, C., Dasari, R. R., Gowthami, M., Varam, N. J., ... \& Musa, G. B. M. (2020). Exfoliation Technique of Composing and Depictions of Clopidogrel Bisulphate Afloat Microspheres. Journal of Evolution of Medical and Dental Sciences, 9(14), 1156-1161.

6. Haznedar, S., \& Dortunc, B. (2004). Preparation and in vitro evaluation of Eudragit microspheres containing acetazolamide. International journal of pharmaceutics, 269(1), 131-140.
7. Hennink, W. E., \& Franssen, $O$. (2002). U.S. Patent No. 6,395,302. Washington, DC: U.S. Patent and Trademark Office.

8. Hindustan A. A., Kumar, C. S., \& Kumar, K. (2010). Designing and evaluation of Diclofenac sodium sustained release matrix tablets using Hibiscus Rosa-Sinensis leaves mucilage. Int J of Pharm Sci Rev and Res, 1 (2), 29-31.

9. Hindustan, A. A., Anuradha, C. M., Kumar, C. S., Reddy, K. K., \& Jagadeesh, K. D. (2010). Novel approach in formulation and evaluation of mouth dissolving tablets of ondansetron hydrochloride. International journal of applied biology and pharmaceutical technology, 1 (2), 582-88.

10. Ishaq, B. M., Ahad, H. A., Muneer, S., \& Praveena, S. (2013). Colourimetric assay of atomoxetine hydrochloride by simple aurum coupling reaction in bulk and tablet dosage form. Glob. J. Med. Res, 13, 70-74.

11.Kumar DJ, Hindustan A, Anuradha C, Chitta S, Reddy K, Savithri R. (2010). Dual acting oral floating matrix tablets of ranitidine hydrochloride. International journal of applied biology and pharmaceutical technology, 1 (2).

12.Ma, N., XU, L., Wang, Q., Zhang, X., Zhang, W., Li, Y., \& Li, S. (2008). Development and evaluation of new sustained-release floating microspheres. International journal of pharmaceutics, 358(1-2), 82-90.

13. Meka, L., Kesavan, B., Chinnala, K. M., Vobalaboina, V., \& Yamsani, M. R. (2008). Preparation of a matrix type multiple-unit gastro retentive floating 
drug delivery system for captopril based on gas formation technique: in vitro evaluation. Aaps

Pharmscitech, 9(2), 612.

14. Mohammed, B. I., Ahad, H. A., Muneer, S., Parveen, S., \& Fahmida, B. (2014). Analytical method development and validation for the estimation of temozolomide in phosphate buffer in $\mathrm{pH} 2.0$ as a solvent by UV spectroscopy. Int Res J Pharm, 5, 17-20.

15. Muneer, S., Ahad, H. A., \& Bonnoth, C. K. (2017). 1Research Scholar, Research and Development, Jawaharlal Nehru Technological University, Anantapur 515002, AP, India. 2Professor and Principal, Balaji College of Pharmacy, Anantapur 515002, AP, India. 3Professor and Director, JNTUA-Oil Technological and Pharmaceutical Research Institute, Jawaharlal Nehru Technological University, Anantapur 515002, AP, India. Journal of Pharmacy Research, $11(6), 712-718$.

16.Rani, M. E., Ahad, H. A., \& Sreenivasulu, R. Mahendra kumar P., Ashwan kumar A. and Siddaiah G., (2011). "Spectrophotometric determination of cefadroxil in pharmaceuticals dosage forms by bromination method". Journal of Pharmacy Research, 4(3), 739-740.

17.Srivastava, A. K., Ridhurkar, D. N., \& Wadhwa, S. (2005). Floating microspheres of cimetidine: Formulation, characterization and in vitro evaluation. Acta Pharmaceutica, 55(3), 277-285. 